\section{Dementia

\title{
Characteristics Associated with Quality of Life in Long-Term Care Residents with Dementia: A Cross-Sectional Study
}

\author{
Maartje S. Klapwijk ${ }^{a}$ b Monique A.A. Caljouw ${ }^{a}$ Marjoleine J.C. Pieper ${ }^{a, c}$ \\ Jenny T. van der Steen ${ }^{a}$ Wilco P. Achterberg ${ }^{a}$ \\ a Department of Public Health and Primary Care, Leiden University Medical Center, Leiden, \\ b Marente, LTCF 'van Wijckerslooth', Oegstgeest, and 'Topaz, LTCF 'Zuydtwijck', Leiden, \\ The Netherlands
}

\section{Key Words}

Quality of life · Long-term care · Dementia - QUALIDEM · Nursing home medicine · Dementia care $\cdot$ Comorbidity $\cdot$ Pain

\begin{abstract}
Background: To determine which characteristics are associated with quality of life (QOL) in residents with moderate to very severe dementia in long-term care facilities (LTCFs). Material and Methods: This was a cross-sectional analysis of a cluster randomized controlled study in 12 Dutch LTCFs that enrolled 288 residents, with moderate to severe dementia assessed with the Reisberg Global Deterioration Scale (Reisberg GDS) and QOL with the QUALIDEM. Characteristics that were hypothesized to be associated with the six domains of QOL (applicable to very severe dementia) included demographic variables, activities of daily living (Katz $A D L$ ), cognitive performance (Cognitive Performance Scale; CPS), pain (Pain Assessment Checklist for Seniors with Limited Ability to Communicate; PACSLAC-D), neuropsychiatric symptoms (Neuropsychiatric Inventory-Nursing Home Version; NPI-NH) and comorbidities. Results: Multivariate logistic regression modelling showed associations with age in the domain Social isolation [odds ratio, OR, 0.95 (95\% confidence interval, CI, 0.91-0.99)], ADL level in the domain Positive affect [OR 0.89 (95\% CI 0.83-0.95)] and the domain Social relations [OR 0.87 (95\% CI $0.81-0.93)$ ], severity of dementia in the domain Social relations [OR 0.28 (95\% CI 0.12-0.62)] and in the domain Social isolation [OR 2.10 (95\% CI 1.17-3.78)], psychiatric disorders in the domain Positive affect [OR 0.39 (95\% CI 0.17-0.87)] and pulmonary diseases in the domain Negative affect [OR 0.14 (95\% CI 0.03-0.61)] of the QUALIDEM. Neuropsychiatric symptoms were independently associated with all six domains of the QUALIDEM [OR 0.93 (95\% CI 0.900.96) to OR 0.97 (95\% CI 0.95-0.99)]. Pain was associated with the domains Care relationship [OR 0.92 (95\% CI 0.84-1.00)] and Negative affect [OR 0.92 (95\% CI 0.85-1.00)]. Conclusion:
\end{abstract}


Klapwijk et al.: Characteristics Associated with Quality of Life in Long-Term Care Residents with Dementia: A Cross-Sectional Study

$\mathrm{QOL}$ in dementia is independently associated with age, $\mathrm{ADL}$, dementia severity, pain, psychiatric disorders, pulmonary diseases and neuropsychiatric symptoms. It is possible to detect persons with dementia at risk for a lower QOL. This information is important for developing personalized interventions to improve $\mathrm{QOL}$ in persons with dementia in LTCFs.

(C) 2016 The Author(s)

Published by S. Karger AG, Basel

\section{Introduction}

With the decrease in functional independency in people with dementia and the need for specialized care, admission to a long-term care setting is often inevitable in later stages of the disease $[1,2]$. Because there is no cure for dementia, care, research and management in longterm care facilities (LTCFs) are primarily focused on improving or maintaining quality of life (QOL) in these vulnerable persons $[3,4]$. In the general population, QOL is often defined as 'individuals' perception of their position in life in the context of the culture and the value systems in which they live and in relation to their goals, expectations, standards and concerns [5].

Measuring QOL in dementia is more challenging due to the fact that persons with dementia often cannot give their own perception, especially when people are in a moderate to severe stage of dementia. Therefore, the definitions of QOL in studies measuring QOL in dementia generally use several dimensions, which reflects that QOL in dementia is a multidimensional concept. Depending on their theoretical background, these different domains can include items related to physical and psychological wellbeing, social interaction, and positive/negative affect [6-9].

To improve QOL for persons with dementia, the factors associated with QOL need to be identified. However, no consistent association has been found between socio-demographic factors (age, gender, race, marital status) and QOL in persons with dementia [10-13]. On the other hand, psychosocial factors such as sadness [14], depression $[4,10,15,16]$ and agitation $[10,16,17]$ have a negative association with QOL, whereas functional characteristics (e.g. ADL impairment and dementia severity) show inconclusive evidence for associations with QOL $[10,12,18-20]$.

Moreover, data are inconclusive regarding physical characteristics. Although some studies confirm a relationship between pain and a lower psychological wellbeing in dementia, the exact relationship between pain and the various domains and the effect on QOL remains unclear [20-23]. In addition, although chronic diseases can have an impact on QOL, information is lacking on their relationship with QOL in persons with dementia [24, 25].

More insight into the factors associated with the different domains of QOL in residents with moderate to very severe dementia in LTCFs may help to better identify persons with dementia with a low QOL on a specific domain. Therefore, this cross-sectional study aimed to explore in more detail which patient characteristics (demographic, psychosocial, functional and physical) are associated with the domains of QOL in people with moderate to very severe dementia in LTCFs.

\section{Material and Methods}

Setting and Study Population

This cross-sectional study uses baseline data of the STA-OP! study, a cluster randomized controlled trial which implemented an intervention to address pain and challenging behavior [26,27]. LTCFs were recruited within the 'University Network for Organizations of Elderly care' of the VU University Medical Center. The aim of this and other academic LTCF networks in the Netherlands is to generate knowledge on the best multidisciplinary care for vulnerable older persons [28, 29]. Participating LTCFs had to meet the following criteria: 
Klapwijk et al.: Characteristics Associated with Quality of Life in Long-Term Care

Residents with Dementia: A Cross-Sectional Study

at least one dementia ward willing to participate and no major organizational changes or building activities planned or performed during the study period.

\section{Inclusion and Exclusion Criteria}

Residents with moderate to very severe dementia were eligible. Dementia severity was assessed with the Reisberg Global Deterioration Scale (Reisberg GDS) by the treating elderly care physician [30]. Residents with a Reisberg GDS score of 5 (moderate dementia), 6 (moderately severe dementia) or 7 (severe dementia) were eligible for this study.

\section{Informed Consent}

Written informed proxy consent was obtained from family/caregivers for all residents meeting the inclusion criteria. The study was approved by the Medical Ethics Review Committee of the VU University Medical Center Amsterdam (Registration No. 2009/119) and was registered in the Dutch Trial Register (NTR-1967).

\section{Data Collection}

Elderly care physicians and registered or certified nurse assistants collected the data [27]. All the following instruments have also been tested and extensively used in the Netherlands.

\section{Quality of Life}

QOL was assessed with the QUALIDEM: this is an observational instrument that measures QOL in persons with dementia and is filled out by the nursing staff, preferably by two nurses [31]. The QUALIDEM is based on the theoretical framework of the adaptation-coping theory. The scale is reliable, easy to administer and provides a QOL profile of persons with dementia in an LTCF setting [18, 32, 33]. The QUALIDEM consists of 37 items describing observable behavior in nine domains: Care relationship, Positive affect, Negative affect, Restless tense behavior, Positive self-image, Social relations, Social isolation, Feeling at home and Having something to do. The QUALIDEM (of 37 questions) takes about $15 \mathrm{~min}$ to fill out and is based on an observation window of 1 week [18]. The response options are: never, rarely, sometimes and frequently. We used the 6 domains (Care relationship, Positive affect, Negative affect, Restless tense behavior, Social relations and Social isolation) that include 18 questions that are also applicable for very severe dementia (GDS 7) [32]. The individual item scores for each domain are processed such that a higher composite score reflects a better QOL. On the domains Care relationship, Restless tense behavior, Social relations and Social isolation, the scores range from 0 to 9, Positive affect scores range from 0 to 12, and Negative affect scores from 0 to 6 . For the logistic regression analysis, two groups were created (high and low QOL) based on the median score for each domain.

\section{Functioning}

ADL functioning was measured with the Katz Index of Independence in activities of daily living (ADL), commonly referred to as the Katz ADL. The Katz ADL is a reliable and valid instrument to assess functional status $[34,35]$. The index ranks adequacy of performance in the six functions of bathing, dressing, toileting, transferring, continence and feeding. The scores on each function are summed; the total range is 6 to 24 with higher score indicating more dependency in ADL.

The 7-category Minimum Data Set Cognitive Performance Scale (CPS) was used to determine cognitive function and was assessed by the elderly care physician. The CPS is a valid measure for cognitive performance and ranges from intact (level 0), borderline intact (1), mild (2), moderate (3), moderately severe (4) and severe impairment (5) to very severe impairment (level 6) [36].

\section{Comorbidity}

Comorbidity was assessed by the elderly care physician with the MDS-RAI comorbidity list that contains the following groups of diseases; endocrine diseases, visual impairments, cardiovascular diseases, psychiatric disorders, pulmonary diseases, diseases of musculoskeletal system, neurological diseases (without Alzheimer disease or other types of dementia), other and infection in the last 7 days [37].

Pain

The PACSLAC-D is a validated and shortened Dutch version of the Pain Assessment Checklist for Seniors with Limited Ability to Communicate [38-40]. The observation was done during morning care by the nursing staff and was filled in afterwards. A total score of $\geq 4$ is indicative of pain [41]. 
Klapwijk et al.: Characteristics Associated with Quality of Life in Long-Term Care Residents with Dementia: A Cross-Sectional Study

Neuropsychiatric Symptoms

The Neuropsychiatric Inventory-Nursing Home Version (NPI-NH) was developed to characterize the psychopathology of patients with dementia. It scores 12 behavioral and psychological areas such as delusions, hallucinations, agitation/aggression, depression/dysphoria, anxiety, euphoria/elation, apathy/indifference, disinhibition, irritability/lability, aberrant motor behavior and two types of neurovegetative changes, i.e. sleep and night-time behavior disorders, and appetite and eating disorders. The product of the frequency and severity ratings provides an overall score for each of the 12 items in a total score ranging from 0 to 144 [42-44]. A higher score indicates more (severe) neuropsychiatric symptoms.

Statistical Analysis

Descriptive statistics were used to describe the study population; results are reported as mean and standard deviation (SD) for normally distributed variables and median and interquartile range (IQR) when nonnormally distributed.

Only the 18 questions of the QUALIDEM that are also applicable for persons with advanced dementia (GDS 7) were used; the score was dichotomized at the median score at each domain. A univariate logistic regression was performed for each characteristic and each separate domain of the QUALIDEM. Results with a $\mathrm{p}$ value $\leq 0.10$, and age and gender, were included in the multivariate logistic regression model for each domain. The relationship between the remaining variables in each domain was calculated using the Pearson's correlation coefficient. In this multivariate model, a p value $<0.05$ was considered statistically significant. The association between the characteristics and QOL were reported as odds ratios (OR) and 95\% confidence intervals (95\% CI). All analyses were performed with the SPSS statistical software, version 20, 2011 (SPSS Inc., IBM, USA).

\section{Results}

\section{Study Population}

Between January 2010 and June 2012, in 12 Dutch LTCFs covering a total of 21 nursing home units, 363 residents were eligible for participation. Of these residents, 56 (15.4\%) were not willing to participate, $13(3.6 \%)$ died before start of the study, $3(0.8 \%)$ did not meet the inclusion criteria of the STA-OP! study and $3(0.8 \%)$ were transferred to another LTCF, leaving 288 participants for the present analysis. Mean age was 83.8 (SD 7.1) years and the median length of stay in the LTCF was 22.4 (IQR 11-40) months (table 1).

All participants were highly dependent regarding ADL: the median Katz score was 18 (IQR 14-22). About half of the participants (52.1\%) had severe (CPS 5) or very severe cognitive (CPS 6) impairment (table 1), 80 (28\%) participants had very severe dementia (GDS 7) and $208(72 \%)$ had moderate to severe dementia (GDS 5 and 6) (table 1).

Regarding comorbidity, 30 (10.4\%) participants had lung diseases, 152 (52.8\%) cardiovascular diseases and $18(6.3 \%)$ had an infection in the last 7 days (table 1). The median pain score (PACSLAC-D) was 3 (IQR 1-7), and the median NPI-NH total score was 12 (IQR 4-23).

\section{Quality of Life}

QUALIDEM Scores per Domain

The median score on the domain Care relationship was 7 (IQR 5-8), on Positive affect 9 (IQR 7-11), on Negative affect 5 (IQR 4-6), on Restless tense behavior 5 (IQR 2-7), on Social relations 6 (IQR 4-8) and on the domain Social isolation the median score was 7 (IQR 5-9).

QUALIDEM Univariate and Multivariate Analysis

The univariate logistic regression showed different results for each domain of the QUALIDEM (table 2). Pain and neuropsychiatric symptoms were univariately associated with all six QUALIDEM domains, ranging for pain from OR 0.82 (95\% CI 0.76-0.89) to OR 0.90 
Table 1. Characteristics of the study population $(n=288)$

\begin{tabular}{|c|c|}
\hline \multicolumn{2}{|l|}{ Demographic variables } \\
\hline Female & $207(71.9 \%)$ \\
\hline Age, mean (SD), years & $83.8(7.1)$ \\
\hline Length of stay, median (IQR), months & $22.4(11-40$ \\
\hline \multicolumn{2}{|l|}{ Marital status } \\
\hline Married/partner & $87(30.2 \%)$ \\
\hline No partner & $201(69.8 \%)$ \\
\hline \multicolumn{2}{|l|}{ Functional variables } \\
\hline Katz range 6-24, median (IQR) & $18(14-22)$ \\
\hline CPS level 0 intact to level 4 moderate severe impairment & $138(47.9 \%)$ \\
\hline CPS level 5 + 6 severe and very severe impairment & $150(52.1 \%)$ \\
\hline \multicolumn{2}{|l|}{ Disease-specific measurements } \\
\hline \multicolumn{2}{|l|}{ Dementia severity } \\
\hline Reisberg GDS 5 and 6 & $208(72 \%)$ \\
\hline Reisberg GDS 7 & $80(28 \%)$ \\
\hline \multicolumn{2}{|l|}{ Comorbidity $(\geq 1)$} \\
\hline Endocrine $^{\mathrm{a}}$ & $78(27.1 \%)$ \\
\hline Vision impairment $\mathrm{t}^{\mathrm{b}}$ & $53(18.4 \%)$ \\
\hline Heart/cardiovascular disease ${ }^{c}$ & $152(52.8 \%)$ \\
\hline Psychiatric/mood ${ }^{\mathrm{d}}$ & $44(15.3 \%)$ \\
\hline Lung disease $\mathrm{e}^{\mathrm{e}}$ & $30(10.4 \%)$ \\
\hline Diseases of musculoskeletal system ${ }^{\mathrm{f}}$ & $75(26.0 \%)$ \\
\hline Neurological diseases ${ }^{g}$ & $71(24.7 \%)$ \\
\hline Otherh & $42(14.6 \%)$ \\
\hline Infection in last 7 days ${ }^{\mathrm{i}}$ & $18(6.3 \%)$ \\
\hline Pain; PACSLAC-D range $0-24$, median (IQR) & $3(1-7)$ \\
\hline Behavior; NPI range $0-144$, median (IQR) & $12(4-23)$ \\
\hline
\end{tabular}

${ }^{\mathrm{a}}$ Diabetes mellitus, hypothyroidism and/or hyperthyroidism. ${ }^{\mathrm{b}}$ Cataract, diabetic retinopathy, glaucoma, and/or macular degeneration. ${ }^{\mathrm{c}}$ Arteriosclerotic disease, heart rhythm disorders, heart failure, hypertension, hypotension, peripheral vascular disease, other. 'd Anxiety disorder, depression, manic depression, schizophrenia. ${ }^{\mathrm{e}}$ Asthma, Emphysema/COPD. ${ }^{\mathrm{f}}$ Rheumatic diseases, hip fracture, amputation, osteoporosis, pathologic bone fracture. ${ }^{g}$ Aphasia, cerebral palsy, stroke, hemiplegia/hemiparesis, paraplegia, multiple sclerosis, Parkinson disease, seizures, transient cerebral ischemia, traumatic brain injury, quadriplegia. ${ }^{\mathrm{h}}$ Allergies, anemia, cancer, renal failure. ${ }^{\mathrm{i}}$ Pneumonia, respiratory tract infection, urinary tract infection; last 30 days.

(95\% CI 0.84-0.96) and ranging for neuropsychiatric symptoms from OR 0.92 (95\% CI 0.890.94 ) to OR 0.97 (95\% CI 0.95-0.98).

The functional variables (Katz and CPS) were associated with the domains Positive affect [Katz: OR 0.88 (95\% CI 0.83-0.92); CPS: OR 0.44 (95\% CI 0.28-0.71)] and Social relations [Katz: OR 0.82 (95\% CI 0.78-0.87); CPS: OR 0.31 (95\% CI 0.19-0.51)]. Compared to lower dementia severity (GDS 5 and 6), very severe dementia (GDS 7) was associated with the domains Positive affect [OR 0.42 (95\% CI 0.25-0.72)], Social relations [OR 0.17 (95\% CI 0.090.33)] and Social isolation [OR 2.20 (95\% CI 1.33-3.71)].

The multivariate logistic regression model (table 3) showed that neuropsychiatric symptoms are independently (negatively) associated with all six domains of the QUALIDEM [OR 0.93 (95\% CI 0.90-0.96) to OR 0.97 (95\% CI 0.95-0.99)].

Pain was (negatively) associated with the domains Care relationship [OR 0.92 (95\% CI 0.84-1.00)] and Negative affect [OR 0.92 (95\% CI 0.85-1.00)], and ADL level (negatively) associated with the domains Positive affect [OR 0.89 (95\% CI 0.83-0.95)] and Social relations 
Dementia

and Geriatric
Dement Geriatr Cogn Disord 2016;42:186-197

191
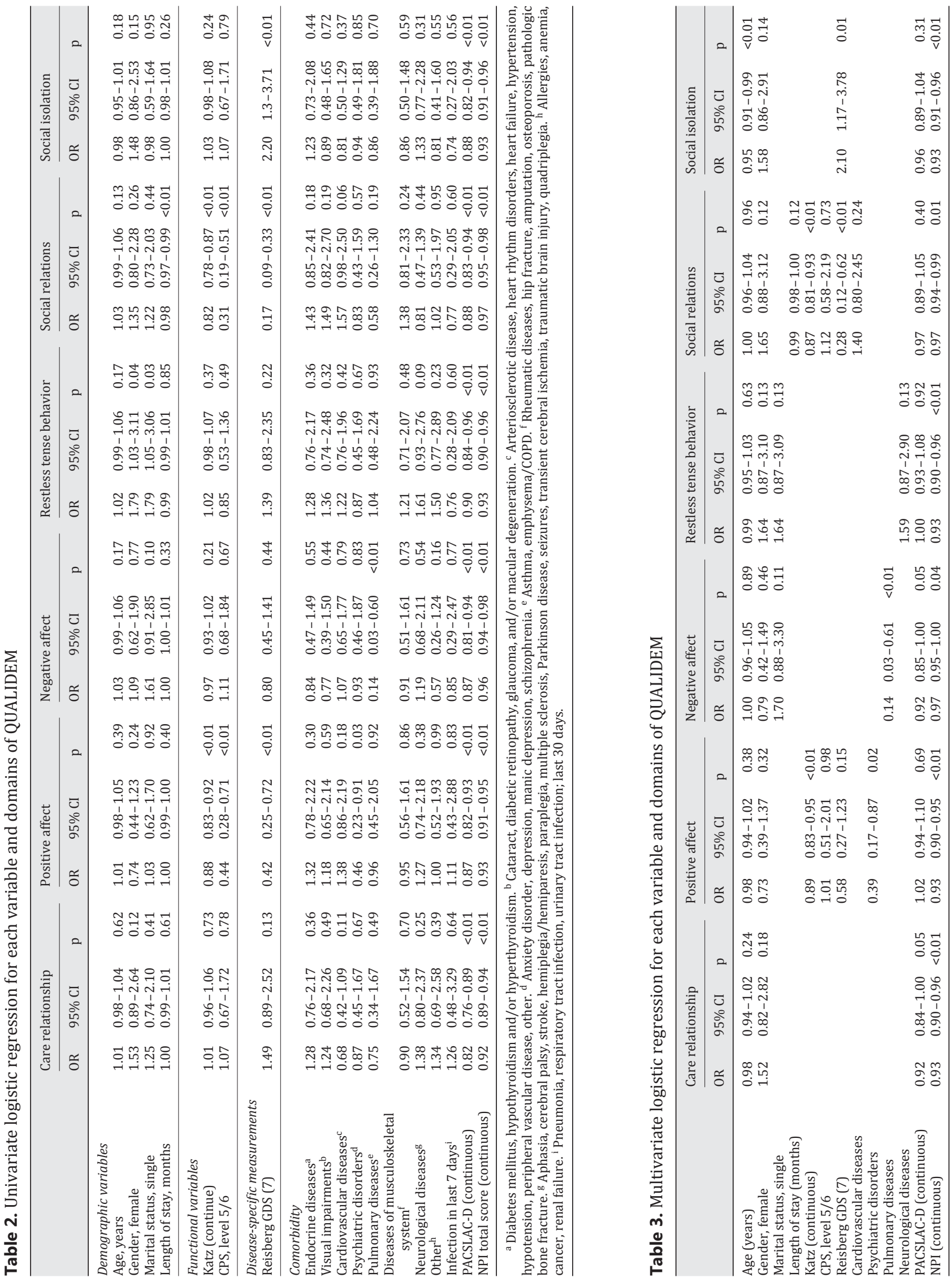
Dementia

and Geriatric

Cognitive Disorders

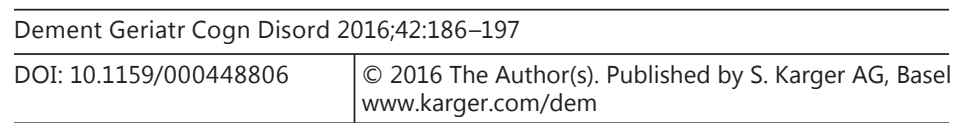

Klapwijk et al.: Characteristics Associated with Quality of Life in Long-Term Care Residents with Dementia: A Cross-Sectional Study

[OR 0.87 (95\% CI 0.81-0.93)]. Dementia severity was (negatively) associated with the domains Social relations [OR 0.28 (95\% CI 0.12-0.62)] and (positively) associated with Social isolation [OR 2.10 (95\% CI 1.17-3.78)]. Age, psychiatric disorders and pulmonary diseases were independently (negatively) associated with one domain of the QUALIDEM, i.e. Social isolation, Positive affect and Negative affect, respectively. The Pearson's correlation coefficients between the characteristics and the QUALIDEM domains were all below 0.55 .

\section{Discussion}

This cross-sectional study explored the association of QOL in persons with dementia in LTCFS with demographic, psychosocial, functional and physical patient characteristics.

Interestingly, different domains showed different associations, which suggests that also interventions to improve QOL might benefit from knowledge of low QOL scores on these specific domains. QOL in persons with dementia is independently associated with different patient characteristics across the QOL domains. In the domain Care relationship, a lower QOL was associated with pain and neuropsychiatric symptoms. In the domain Positive affect, an association with a lower QOL was found with more ADL dependency, psychiatric disorders and neuropsychiatric symptoms. In the domain Negative affect, an association was found with a lower QOL and pulmonary diseases, pain and neuropsychiatric symptoms. In Restless tense behavior, an association was found with neuropsychiatric symptoms. In the domain Social relations, an association was found with a lower QOL and more ADL dependency, a more severe dementia and neuropsychiatric symptoms. In the domain Social isolation, an association was found between a lower QOL and a higher age and neuropsychiatric symptoms, and, remarkably, a higher QOL was associated with more severe dementia.

The present study confirms that QOL should be approached and measured as a multidimensional construct and not as a single construct [8]. The study also shows that it is possible to detect which people are at risk for a lower QOL across different QOL domains. These QOL domains, with their own specific relationships with functional and other patient characteristics, should be taken into account when selecting person-centered interventions to improve QOL in persons with dementia.

With a decrease in ADL functioning, the domain Positive affect and Social relations are threatened. Higher age and less severe dementia imply that persons with dementia are more vulnerable to social isolation. Interventions on neuropsychiatric symptoms may have a beneficial influence on all domains of QOL, and the potential of especially nonpharmacological interventions are very promising [45].

To our knowledge, this is the first study to examine QOL in relation to pain and comorbidity in a large group of persons with dementia in LTCFs. The relationships found between QOL and pain and comorbidity is highly relevant to improve QOL in persons with dementia in LTCFs. Since pain can be related to neuropsychiatric behavior, this may influence QOL [46-48]. Treatment of pain and optimization of symptom control for patients with a psychiatric disorder or pulmonary disease may result in a higher QOL, which is also suggested by studies in the general population [49]. Comorbidity in general, however, seems to have little impact on QOL in persons with moderate to severe dementia.

\section{Strengths and Limitations}

Although self-report is the preferred method of assessing QOL, persons with dementia are often incapable of evaluating their own QOL, especially in the later stages of the disease. Different observational methods are available and validated to measure QOL in persons with moderate to severe dementia in LTCFs [7, 50-53], and some have good psychometric prop- 
Klapwijk et al.: Characteristics Associated with Quality of Life in Long-Term Care Residents with Dementia: A Cross-Sectional Study

erties $[8,9]$. These observational instruments employ different domains of QOL that are important for persons with dementia. The QUALIDEM is recommended to evaluate QOL in severe dementia [9]; it focuses on the QOL domains that are judged important for persons with dementia, even in severe end-stage dementia [54]. Although other QOL instruments, such as the QUALID, are also developed to measure QOL in this population, the specific characteristic of the QUALIDEM is the differentiation in separate domains of QOL. A strength of the present study was the use of the QUALIDEM in a large group of people with moderate to severe dementia. Although the QUALIDEM is a reliable instrument to measure QOL, it takes 15 min to complete all 37 questions. Due to the pragmatic character of this study, reflecting daily care for persons with dementia in LTCF, only one (contact) nurse of the patient (instead of two nurses) filled the instrument; this is a limitation of the study because the developers of the QUALIDEM advise to use the answers reached by a consensus between two nurses. In the present study only the 18 questions suitable for very severe dementia (GDS 7) were used, because these questions are reliable for use in patients with mild dementia as well as those with very severe dementia $[18,32,55]$. A short instrument that can be filled out by one person would be more feasible [20,56]. For future studies and implementation in LTCFs, we recommend using the shorter version (18 items) of the QUALIDEM that is applicable to all levels of dementia severity. Such an easy-to-use instrument would stimulate use in clinical practice and research on QOL in persons in LTCFs, including those with very severe dementia. In the present study, almost $30 \%$ of the participants had very severe dementia. These advantages should however be evaluated against a less in-depth evaluation of QOL in less advanced dementia patients.

Although this study was embedded in a cluster randomized controlled trial with possible selection bias, almost all patients met the inclusion criteria, and about $85 \%$ agreed to participate. The average age and the proportion of males/females are comparable to other studies performed in LTCF $[2,18]$. Moreover, the QUALIDEM scores were also similar to those in other studies on persons with dementia $[18,57,58]$.

Family members often rate the QOL of their relative lower compared to self-reported ratings $[59,60]$. The differences in the rating of QOL between self-report and proxy report generally depend on variables such as depressive symptoms and severity of dementia and should be recognized [55, 61-64]. The QUALIDEM was developed to measure QOL in persons with dementia; however, observational instruments always have the possibility of observer bias [65]. The QUALIDEM was the last instrument filled by the nurse, and recall of earlier items could have influenced the answers. Finally, because we used several outcomes in different domains with several potential determinants, we acknowledge that multiple testing may have led to some results being the result of chance.

It is difficult to study QOL in people with a progressive disease that is characterized by loss of various cognitive functions. Many studies in persons with dementia have resulted in more knowledge on different aspects of QOL and the various factors that can help to improve or maintain QOL. This study shows that it is possible to detect which persons with dementia are at risk for a lower QOL across different QOL domains; therefore, it seems possible to target interventions to improve QOL. Interventions such as group cognitive stimulation therapy (GCST) [66], integrated emotion-oriented care [67], emotional adaptation [68], improving pain management [23] and research on the effect of organization of LTCF [69], and the effect of an outdoor space such as a garden [70], show promise with regard to the aim of improving QOL in persons with dementia.

A Cochrane analysis showed a positive effect of exercise on ADL and depression but, unfortunately, many of the included studies did not specifically include QOL as a primary outcome [71, 72]. Also, because different methods (with different components) were used to measure QOL, it is difficult to compare the results of studies on QOL. 
In the present study, the QUALIDEM data are the result of a 1-week observation period in the life of a person with dementia. The next step is to repeat the measurements and test whether the QOL changes over time with the progression of the disease. Another possibility is to examine the individual characteristics of persons with dementia that are related to QOL and follow the effects of interventions on the different domains of QOL [73]. The different domains that are relevant in QOL may respond differently to various interventions.

\section{Conclusion}

QOL in dementia is independently associated with age, ADL, dementia severity, pain, psychiatric disorders, pulmonary diseases and neuropsychiatric symptoms. It is possible to detect persons with dementia at risk of a lower QOL. This information is important to develop personalized interventions to improve QOL in persons with dementia in LTCFs.

\section{Acknowledgments}

Funding: The STA-OP! study was funded by Innovatiefonds Zorgverzekeraars, the Netherlands. They had no role in the study design, data collection, data analysis or writing of the report.

\section{Disclosure Statement}

The authors declare that they have no conflict of interest.

\section{References}

1 Reyniers T, Deliens L, Pasman HR, Morin L, Addington-Hall J, Frova L, Cardenas-Turanzas M, Onwuteaka-Philipsen B, Naylor W, Ruiz-Ramos M, et al: International variation in place of death of older people who died from dementia in 14 European and non-European countries. J Am Med Dir Assoc 2015;16:165-171.

2 Caljouw MA, Cools HJ, Gussekloo J: Natural course of care dependency in residents of long-term care facilities: prospective follow-up study. BMC Geriatr 2014;14:67.

3 Moyle WM, et al: Quality of life and dementia. The voice of the person with dementia. Dementia (London) 2007;6:175-191.

4 Beerens HC, Sutcliffe C, Renom-Guiteras A, Soto ME, Suhonen R, Zabalegui A, Bokberg C, Saks K, Hamers JP: Quality of life and quality of care for people with dementia receiving long term institutional care or professional home care: the European Right Time Place Care study. J Am Med Dir Assoc 2014;15:54-61.

5 Kuyken W: The World Health Organization Quality of Life assessment (WHOQOL): position paper from the World Health Organization. Soc Sci Med (1982) 1995;41:1403-1409.

6 Jonker C, Gerritsen DL, Bosboom PR, Van Der Steen JT: A model for quality of life measures in patients with dementia: Lawton's next step. Dement Geriatr Cogn Disord 2004;18:159-164.

7 Ettema TP, Droes RM, de Lange J, Mellenbergh GJ, Ribbe MW: A review of quality of life instruments used in dementia. Qual Life Res 2005;14:675-686.

8 Perales J, Cosco TD, Stephan BC, Haro JM, Brayne C: Health-related quality-of-life instruments for Alzheimer's disease and mixed dementia. Int Psychogeriatr 2013;25:691-706.

9 Aspden T, Bradshaw SA, Playford ED, Riazi A: Quality-of-life measures for use within care homes: a systematic review of their measurement properties. Age Ageing 2014;43:596-603.

10 Beerens HC, Zwakhalen SM, Verbeek H, Ruwaard D, Hamers JP: Factors associated with quality of life of people with dementia in long-term care facilities: a systematic review. Int J Nurs Stud 2013;50:1259-1270.

11 Shippee TP, Henning-Smith C, R LK, Lewis T: Resident- and facility-level predictors of quality of life in longterm care. Gerontologist 2015;55:643-655.

12 Mjorud M, Kirkevold M, Rosvik J, Selbaek G, Engedal K: Variables associated to quality of life among nursing home patients with dementia. Aging Ment Health 2014;18:1013-1021.

13 Perales J, Cosco TD, Stephan BC, Fleming J, Martin S, Haro JM, Brayne C: Health-related quality of life in the Cambridge City over-75s Cohort (CC75C): development of a dementia-specific scale and descriptive analyses. BMC Geriatr 2014;14:18. 
Klapwijk et al.: Characteristics Associated with Quality of Life in Long-Term Care

Residents with Dementia: A Cross-Sectional Study

14 O'Rourke HM, Duggleby W, Fraser KD, Jerke L: Factors that affect quality of life from the perspective of people with dementia: a metasynthesis. J Am Geriatr Soc 2015;63:24-38.

15 Banerjee S, Samsi K, Petrie CD, Alvir J, Treglia M, Schwam EM, del Valle M: What do we know about quality of life in dementia? A review of the emerging evidence on the predictive and explanatory value of disease specific measures of health related quality of life in people with dementia. Int J Geriatr Psychiatry 2009;24:15-24.

16 Wetzels RB, Zuidema SU, de Jonghe JF, Verhey FR, Koopmans RT: Determinants of quality of life in nursing home residents with dementia. Dement Geriatr Cogn Disord 2010;29:189-197.

17 Gomez-Gallego M, Gomez-Amor J, Gomez-Garcia J: Determinants of quality of life in Alzheimer's disease: perspective of patients, informal caregivers, and professional caregivers. Int Psychogeriatr 2012;24:18051815.

18 Bouman AI, Ettema TP, Wetzels RB, van Beek AP, de Lange J, Droes RM: Evaluation of QUALIDEM: a dementiaspecific quality of life instrument for persons with dementia in residential settings; scalability and reliability of subscales in four Dutch field surveys. Int J Geriatr Psychiatry 2011;26:711-722.

19 Barca ML, Engedal K, Laks J, Selbaek G: Quality of life among elderly patients with dementia in institutions. Dement Geriatr Cogn Disord 2011;31:435-442.

20 Cordner Z, Blass DM, Rabins PV, Black BS: Quality of life in nursing home residents with advanced dementia. J Am Geriatr Soc 2010;58:2394-2400.

21 Galindo-Garre F, Volicer L, van der Steen JT: Factors related to rejection of care and behaviors directed towards others: a longitudinal study in nursing home residents with dementia. Dement Geriatr Cogn Disord Extra 2015;5:123-134.

22 Burfield AH, Wan TT, Sole ML, Cooper JW: Behavioral cues to expand a pain model of the cognitively impaired elderly in long-term care. Clin Intervent Aging 2012; 7:207-223.

23 Lee KH, McConnell ES, Knafl GJ, Algase DL: Pain and psychological well-being among people with dementia in long-term care. Pain Med (Malden) 2015;16:1083-1089.

24 Castro-Monteiro E, Forjaz MJ, Ayala A, Rodriguez-Blazquez C, Fernandez-Mayoralas G, Diaz-Redondo A, Martinez-Martin P: Change and predictors of quality of life in institutionalized older adults with dementia. Qual Life Res 2014;23:2595-2601.

25 Martin-Garcia S, Rodriguez-Blazquez C, Martinez-Lopez I, Martinez-Martin P, Forjaz MJ: Comorbidity, health status, and quality of life in institutionalized older people with and without dementia. Int Psychogeriatr 2013; 25:1077-1084

26 Pieper MJ, Achterberg WP, Francke AL, van der Steen JT, Scherder EJ, Kovach CR: The implementation of the serial trial intervention for pain and challenging behaviour in advanced dementia patients (STA OP!): a clustered randomized controlled trial. BMC Geriatr 2011;11:12.

27 Pieper MJ, Francke AL, van der Steen JT, Scherder EJ, Twisk JW, Kovach CR, Achterberg WP: Effects of a stepwise multidisciplinary intervention for challenging behavior in advanced dementia: a cluster randomized controlled trial. J Am Geriatr Soc 2016;64:261-269.

28 Achterberg WPC, et al: Towards academic nursing home medicine: a Dutch example for Norway? OMSORG 2015;1:10-15.

29 Koopmans RT, Lavrijsen JC, Hoek F: Concrete steps toward academic medicine in long term care. J Am Med Dir Assoc 2013;14:781-783.

30 Reisberg B, Ferris SH, de Leon MJ, Crook T: The Global Deterioration Scale for assessment of primary degenerative dementia. Am J Psychiatry 1982;139:1136-1139.

31 Ettema TP, Droes RM, de Lange J, Mellenbergh GJ, Ribbe MW: QUALIDEM: development and evaluation of a dementia specific quality of life instrument - validation. Int J Geriatr Psychiatry 2007;22:424-430.

32 Ettema TP, Droes RM, de Lange J, Mellenbergh GJ, Ribbe MW: QUALIDEM: development and evaluation of a dementia specific quality of life instrument. Scalability, reliability and internal structure. Int J Geriatr Psychiatry 2007;22:549-556.

33 Graske J, Verbeek H, Gellert P, Fischer T, Kuhlmey A, Wolf-Ostermann K: How to measure quality of life in shared-housing arrangements? A comparison of dementia-specific instruments. Qual Life Res 2014;23:549559.

34 Katz S, Downs TD, Cash HR, Grotz RC: Progress in development of the index of ADL. Gerontologist 1970;10: 20-30.

35 Katz S, Ford AB, Moskowitz RW, Jackson BA, Jaffe MW: Studies of illness in the aged. The index of ADL: a standardized measure of biological and psychosocial function. JAMA 1963;185:914-919.

36 Hartmaier SL, Sloane PD, Guess HA, Koch GG, Mitchell CM, Phillips CD: Validation of the Minimum Data Set Cognitive Performance Scale: agreement with the Mini-Mental State Examination. J Gerontol A Biol Sci Med Sci 1995;50:M128-M133.

37 Fries BE, Simon SE, Morris JN, Flodstrom C, Bookstein FL: Pain in U.S. nursing homes: validating a pain scale for the minimum data set. Gerontologist 2001;41:173-179.

38 Fuchs-Lacelle S, Hadjistavropoulos T: Development and preliminary validation of the pain assessment checklist for seniors with limited ability to communicate (PACSLAC). Pain Manag Nurs 2004;5:37-49.

39 Zwakhalen SM, Hamers JP, Abu-Saad HH, Berger MP: Pain in elderly people with severe dementia: a systematic review of behavioural pain assessment tools. BMC Geriatr 2006;6:3.

40 Zwakhalen SM, Hamers JP, Berger MP: Improving the clinical usefulness of a behavioural pain scale for older people with dementia. J Adv Nurs 2007;58:493-502. 
41 Zwakhalen SM, Koopmans RT, Geels PJ, Berger MP, Hamers JP: The prevalence of pain in nursing home residents with dementia measured using an observational pain scale. Eur J Pain (London) 2009;13:89-93.

42 Cummings JL: The Neuropsychiatric Inventory: assessing psychopathology in dementia patients. Neurology 1997;48(suppl 6):S10-S16.

43 Cummings JL, Mega M, Gray K, Rosenberg-Thompson S, Carusi DA, Gornbein J: The Neuropsychiatric Inventory: comprehensive assessment of psychopathology in dementia. Neurology 1994;44:2308-2314.

44 Kat MG, de Jonghe JF, Aalten P, Kalisvaart CJ, Droes RM, Verhey FR: Neuropsychiatric symptoms of dementia: psychometric aspects of the Dutch Neuropsychiatric Inventory (NPI). Tijdschr Gerontol Geriatr 2002;33:150155.

45 Livingston G, Kelly L, Lewis-Holmes E, Baio G, Morris S, Patel N, Omar RZ, Katona C, Cooper C: Non-pharmacological interventions for agitation in dementia: systematic review of randomised controlled trials. $\mathrm{Br} \mathrm{J}$ Psychiatry 2014;205:436-442.

46 van Dalen-Kok AH, Pieper MJ, de Waal MW, Lukas A, Husebo BS, Achterberg WP: Association between pain, neuropsychiatric symptoms, and physical function in dementia: a systematic review and meta-analysis. BMC Geriatr 2015;15:49.

47 van Dalen-Kok AH, Pieper M, de Waal M, Lukas A, Husebo BS, Achterberg WP: Erratum to: Association between pain, neuropsychiatric symptoms, and physical function in dementia: a systematic review and meta-analysis. BMC Geriatr 2015;15:109.

48 Pieper MJ, van Dalen-Kok AH, Francke AL, van der Steen JT, Scherder EJ, Husebo BS, Achterberg WP: Interventions targeting pain or behaviour in dementia: a systematic review. Ageing Res Rev 2013;12:1042-1055.

49 Sprangers MA, de Regt EB, Andries F, van Agt HM, Bijl RV, de Boer JB, Foets M, Hoeymans N, Jacobs AE, Kempen GI, et al: Which chronic conditions are associated with better or poorer quality of life? J Clin Epidemiol 2000; 53:895-907.

50 Finnema E, Droes RM, Ribbe M, van Tilburg W: A review of psychosocial models in psychogeriatrics: implications for care and research. Alzheimer Dis Assoc Disord 2000;14:68-80.

51 Scholzel-Dorenbos CJ, van der Steen MJ, Engels LK, Olde Rikkert MG: Assessment of quality of life as outcome in dementia and MCI intervention trials: a systematic review. Alzheimer Dis Assoc Disord 2007;21:172-178.

52 Cadieux MA, Garcia LJ, Patrick J: Needs of people with dementia in long-term care: a systematic review. Am J Alzheimers Dis Other Dement 2013;28:723-733.

53 Orgeta V, Orrell M, Hounsome B, Woods B: Self and carer perspectives of quality of life in dementia using the QoL-AD. Int J Geriatr Psychiatry 2015;30:97-104.

54 Dichter MN, Schwab CG, Meyer G, Bartholomeyczik S, Dortmann O, Halek M: Measuring the quality of life in mild to very severe dementia: testing the inter-rater and intra-rater reliability of the German version of the QUALIDEM. Int Psychogeriatr 2014;26:825-836.

55 Bowling A, Rowe G, Adams S, Sands P, Samsi K, Crane M, Joly L, Manthorpe J: Quality of life in dementia: a systematically conducted narrative review of dementia-specific measurement scales. Aging Ment Health 2015;19:13-31.

56 Terada S, Oshima E, Ikeda C, Hayashi S, Yokota O, Uchitomi Y: Development and evaluation of a short version of the quality of life questionnaire for dementia. Int Psychogeriatr 2015;27:103-110.

57 van de Ven-Vakhteeva J, Bor H, Wetzels RB, Koopmans RT, Zuidema SU: The impact of antipsychotics and neuropsychiatric symptoms on the quality of life of people with dementia living in nursing homes. Int J Geriatr Psychiatry 2013;28:530-538.

58 Dichter MN, Quasdorf T, Schwab CG, Trutschel D, Haastert B, Riesner C, Bartholomeyczik S, Halek M: Dementia care mapping: effects on residents' quality of life and challenging behavior in German nursing homes. A quasiexperimental trial. Int Psychogeriatr 2015;27:1875-1892.

59 Conde-Sala JL, Rene-Ramirez R, Turro-Garriga O, Gascon-Bayarri J, Campdelacreu-Fumado J, Juncadella-Puig M, Rico-Pons I, Garre-Olmo J: Severity of dementia, anosognosia, and depression in relation to the quality of life of patients with Alzheimer disease: discrepancies between patients and caregivers. Am J Geriatr Psychiatry 2014;22:138-147.

60 Arons AM, Krabbe PF, Scholzel-Dorenbos CJ, van der Wilt GJ, Rikkert MG: Quality of life in dementia: a study on proxy bias. BMC Med Res Methodol 2013;13:110.

61 Buckley T, Fauth EB, Morrison A, Tschanz J, Rabins PV, Piercy KW, Norton M, Lyketsos CG: Predictors of quality of life ratings for persons with dementia simultaneously reported by patients and their caregivers: the Cache County (Utah) Study. Int Psychogeriatr 2012;24:1094-1102.

62 Crespo M, Hornillos C, Gomez MM: Assessing quality of life of nursing home residents with dementia: feasibility and limitations in patients with severe cognitive impairment. Int Psychogeriatr 2013;25:1687-1695.

63 Graske J, Meyer S, Wolf-Ostermann K: Quality of life ratings in dementia care - a cross-sectional study to identify factors associated with proxy-ratings. Health Qual Life Outcomes 2014;12:1.

64 Tay L, Chua KC, Chan M, Lim WS, Ang YY, Koh E, Chong MS: Differential perceptions of quality of life (QoL) in community-dwelling persons with mild-to-moderate dementia. Int Psychogeriatr 2014;26:1273-1282.

65 Ettema TP, Droes RM, de Lange J, Ooms ME, Mellenbergh GJ, Ribbe MW: The concept of quality of life in dementia in the different stages of the disease. Int Psychogeriatr 2005;17:353-370.

66 Cooper C, Mukadam N, Katona C, Lyketsos CG, Ames D, Rabins P, Engedal K, de Mendonca Lima C, Blazer D, Teri L, et al: Systematic review of the effectiveness of non-pharmacological interventions to improve quality of life of people with dementia. Int Psychogeriatr 2012;24:856-870. 
67 van der Kooij CH, Droes RM, de Lange J, Ettema TP, Cools HJ, van Tilburg W: The implementation of integrated emotion-oriented care: did it actually change the attitude, skills and time spent of trained caregivers? Dementia (London) 2013;12:536-550.

68 Finnema E, Droes RM, Ettema T, Ooms M, Ader H, Ribbe M, van Tilburg W: The effect of integrated emotionoriented care versus usual care on elderly persons with dementia in the nursing home and on nursing assistants: a randomized clinical trial. Int J Geriatr Psychiatry 2005;20:330-343.

69 Willemse BM, Smit D, de Lange J, Pot AM: Nursing home care for people with dementia and residents' quality of life, quality of care and staff well-being: design of the Living Arrangements for people with Dementia (LAD)study. BMC Geriatr 2011;11:11.

70 Whear R, Coon JT, Bethel A, Abbott R, Stein K, Garside R: What is the impact of using outdoor spaces such as gardens on the physical and mental well-being of those with dementia? A systematic review of quantitative and qualitative evidence. J Am Med Dir Assoc 2014;15:697-705.

71 Forbes D, Forbes SC, Blake CM, Thiessen EJ, Forbes S: Exercise programs for people with dementia. Cochrane Database Syst Rev 2015;4:CD006489.

72 Forbes D, Thiessen EJ, Blake CM, Forbes SC, Forbes S: Exercise programs for people with dementia. Cochrane Database Syst Rev 2013;12:CD006489.

73 Van Mierlo LD, Van der Roest HG, Meiland FJ, Droes RM: Personalized dementia care: proven effectiveness of psychosocial interventions in subgroups. Ageing Res Rev 2010;9:163-183. 